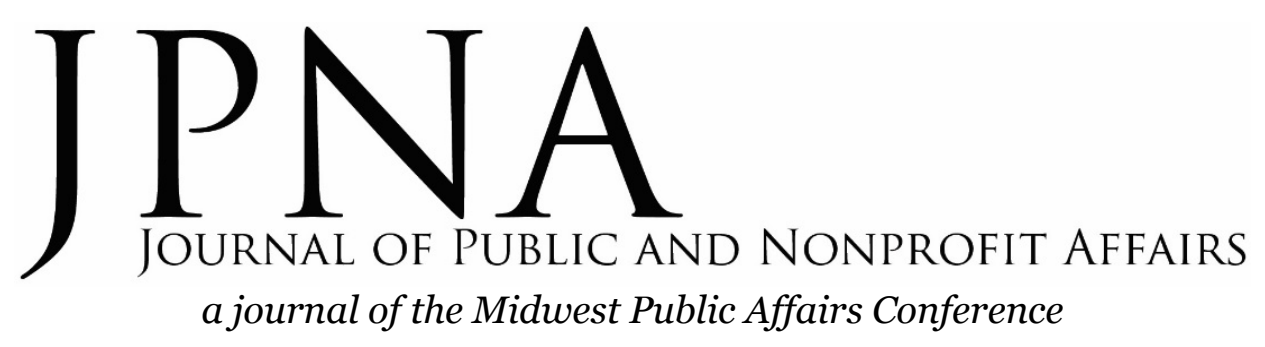

\title{
Summer 2019
}

Volume 5, Number 2

Introduction to the Issue

Lindsey M. McDougle . .............................. 115

\section{Research Articles}

Bridging the Gaps: Local Government and Nonprofit Collaborations

Todd Collins and John David Gerlach ........................... 118

Does Person-Organization Fit Mediate the Relationship between Affect-Based Work

Antecedents and Public Employee Job Satisfaction?

Sungdae Lim, Keon-Hyung Lee, and Kwi-Hee Bae .................... 134

Who is Engaged and Why? Testing an Instrumental Perspective on Stakeholder

Engagement

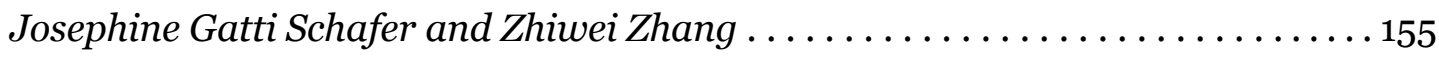

Local Regulation of Charitable Solicitation

Joseph W. Mead ...................................... 178

Citizen Perceptions of Government Policy Success: A Cross-National Study

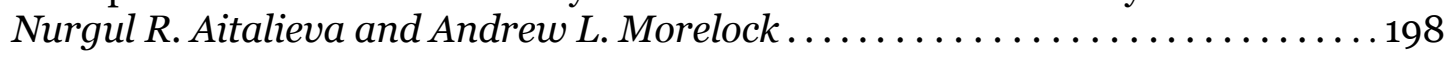

\section{Current Issues in Practice}

Priority Issues from a Health Implementation Plan: A Qualitative Study of Local

Foundation and Nonprofit Leaders' Perceptions

Daniel J. Schober, Shannon M. E. Bowers, and Anne Posner. . . . . . . . . . . . 217

\section{Book Review}

Corruption, Accountability, and Discretion Edited by Nancy S. Lind and

Cara E. Rabe-Hemp

Tyler J. Klatt

232 
